\title{
O ENSINO DE LÍNGUA MATERNA COM TIRINHA UMA ANÁLISE SOCIOCOGNITIVA
}

\author{
Fabiana Silva de Souza é mestranda em Linguística na UERJ. \\ E-mail: $\underline{\text { fabi_ssouza@yahoo.com.br }}$
}

\begin{abstract}
Resumo
O objetivo deste artigo é fazer uma análise dos processos cognitivos presentes na construção do conhecimento, enfatizando projeções e mesclagem. Foram realizadas atividades de compreensão e análise de duas tirinhas com alunos no ensino de língua materna, sob os pressupostos da Linguística Cognitiva.
\end{abstract}

\begin{abstract}
The aim o this paper is to analyze the cognitive process present in the construction of knowledge, emphasizing projections and blending. Activities were understanding and analysis of two strip comic with students in the teaching of mother tongue, under the assumptions of Cognitive Linguistics.
\end{abstract}

\section{1) Introdução}

A partir de nossa experiência em sala de aula do Ensino Fundamental e do Ensino Médio, a escolha em trabalhar com tirinhas deve-se, sobretudo, à dificuldade de leitura e compreensão desse gênero por parte dos discentes e pela constatação do elevado índice de popularidade do gênero história em quadrinhos entre alunos, de qualquer faixa etária, do Ensino Fundamental de escolas públicas e privadas e pelo seu aparecimento em jornais, livros didáticos, internet etc.

A leitura de tiras, mesmo sendo de grande penetração no cotidiano de muitos alunos, apresenta certas dificuldades, conforme os trabalhos desenvolvidos por RAMOS (2005), MORAIS (2005) e SALIÉS (2001), porque nem sempre a interpretação e a compreensão do texto que ali se apresentam são efetivadas. Uma das motivações deste estudo é buscar a aplicação e o uso do gênero tira em sala de aula nas diferentes propostas de ensino de língua portuguesa em nível de ensino básico.

Para tanto, replicando o estudo já realizado por MORAIS (2005), foram realizadas práticas pedagógicas com tiras de O Menino Maluquinho, de Ziraldo e Turma da Mônica, de Maurício de Souza, com alunos de $9^{\circ}$ ano de uma escola pública do município de Duque de Caxias, no Rio de Janeiro. Tais práticas visam à descrição por parte dos alunos acerca daquilo que compreenderam ao realizar a leitura dos materiais. Nosso intuito, ao realizar essas práticas, é estudar o processo de construção do conhecimento por parte dos discentes nas leituras dessas tiras, tendo como suporte a filosofia da Linguística Cognitiva por meio dos processos de projeções metafóricas e mesclagem. 


\section{2) Arcabouço teórico}

Os pressupostos basilares da Linguística Cognitiva afirmam que esta escola vê a língua como o instrumento que utilizamos para demonstrar pensamentos e interagir em sociedade. Com isso, a gramática não é mais um conjunto de regras, mas algo que engloba um conjunto de princípios gerais e processuais operando sobre bases de conhecimento. Os significados são contextualmente construídos, baseados no uso real da língua por um falante ativo e participativo no processo de construção do conhecimento (CHIAVEGATTO, 2009). Ou seja, a linguagem é uma das muitas faculdades cognitivas e se dá pelo social, envolvendo processos dinâmicos para a construção do significado, visto que este é construído por meio de processos mentais através de uma inter-relação entre linguagem e conhecimento, é direcionado por pistas linguísticas presentes no texto e é validada pelo contexto comunicativo.

A teoria sociocognitivista tem um caráter experiencialista, visto que as análises são realizadas em contextos reais de uso, já que a linguagem simplesmente reflete a nossa visão de mundo. Porém, a realidade não é objetivamente dada, sendo em grande parte construída pela natureza corporificada do ser humano. A cognição corporificada reflete a ideia de abordagem da natureza da relação entre mente, linguagem e experiência. A linguística cognitiva é composta por duas visões complementares: a semântica cognitiva que estuda a relação entre a cognição, a experiência corporificada e a linguagem; e a abordagem cognitiva da gramática que estuda as unidades simbólicas que compõem a linguagem.

A visão sociointeracional de leitura assume a posição de que "a língua é um sistema de práticas com o qual os falantes/ouvintes (escritores/leitores) agem e expressam suas intenções com ações adequadas aos objetivos em cada circunstância, mas não construindo tudo como se fosse uma pressão externa pura e simples" (MARCUSCHI, 2008:61). Essa perspectiva prevê que a compreensão envolve uma associação entre o conhecimento prévio do leitor, com toda sua capacidade de realizar inferências, estabelecer intertextualidades e coerências etc. com as informações obtidas através do texto. As pistas linguísticas presentes nos textos abrem espaço para a realização de processos cognitivos, possibilitando a construção de sentido por parte do sujeito.

A abordagem sociocognitivista não distingue conhecimento linguístico de conhecimento de mundo. O conhecimento é enciclopédico, não podendo ser dissociado da utilização da linguagem; logo, o significado é de natureza pragmática, porque a linguagem utilizada é situada e, portanto contextualizada, por definição (EVANS \& GREEN, 2006).

A categorização é a nossa capacidade de identificar, perceber semelhanças e diferenças entre as entidades e, portanto agrupá-las. Visto que esse é um dos princípios basilares da Linguística Cognitiva, pois a linguagem tem como função categorizar o 
mundo, então ela representa um meio de os indivíduos, através de suas experiências e de sua cultura, interpretar o mundo a sua volta.

Lakoff (1987 apud Evans \& Green, 2006), a partir da categorização, desenvolveu a Teoria dos Modelos Cognitivos Idealizados (MCIs) que são representações mentais relativamente estáveis, armazenados na memória de longo prazo, que representam as teorias sobre o mundo, ou seja, são arquivos de memória responsáveis por organizar e classificar nosso pensamento. Miranda (1999:83) afirma que os MCIs são "conhecimentos socialmente produzidos e culturalmente disponíveis. Têm esses conhecimentos papel crucial na cognição humana, qual seja, o de possibilitar o domínio, a lembrança e o uso de um vasto conjunto de conhecimentos na vida diária”, ou seja, os MCIs são construídos com base em nossa cultura, em nossas crenças, em nosso conhecimento de mundo, por meio das experiências que vivenciamos. Então, são modificáveis, isto é, podem se expandir na medida em que nosso conhecimento de mundo se altera. O papel dos MCIs é proporcionar o conhecimento de fundo que pode ser recrutado a fim de estruturar os espaços mentais.

Em relação às molduras comunicativas, estas são, conforme definições de Tannem e Wallat (1987 apud Miranda, 1999), “frames de interação”. Permitem a organização de um determinado evento, visto que estabelecem diferentes enquadres. "São conhecimentos operativos configurados no evento. Incluem entidades, papéis sociais, agenda de encontro, alinhamento, permitindo a identificação do que está sendo posto em movimento na interação" (MIRANDA, 1999:84).

Um elemento importante na construção de significados é conhecido como a Teoria dos Espaços Mentais, desenvolvida por Gilles Fauconnier (1997). Essa abordagem nos orienta que a construção de significados é feita diretamente no contexto, visto que as sentenças não podem ser analisadas isoladamente. Segundo Fauconnier (1997), a construção do significado envolve a construção dos espaços mentais e a criação de mapeamentos entre esses espaços. É um processo fundamentalmente conceitual, que leva em conta os processos cognitivos gerais e princípios que auxiliam essa construção como os mecanismos de projeção conceptual.

Os espaços mentais são domínios locais, disponíveis na memória de trabalho em que são processadas as informações. Possuem um caráter dinâmico e se modificam a cada produção de enunciados, são abertos em proporção ao discurso e são baseados no contexto e nas expressões linguísticas - recursos gramaticais - denominados Construtores de Espaços Mentais. Os MCIs, que são estruturas conceptuais armazenadas na memória de longo prazo, estruturam os espaços mentais, fornecendo informações necessárias. Os Construtores de Espaços Mentais (CE) "em nível gramatical apresentam formas variadas: são sintagmas preposicionais, sintagmas adverbiais, conectivos, sentenças, marcas de tempo e modo verbal" (MIRANDA, 1999:86). 
De acordo com Chiavegatto (2009:91) "é nos espaços de trabalho, transitórios e ajustáveis às situações que organizamos o pensamento em linguagem, processando gramática e semanticamente os enunciados".

Os esquemas imagéticos (Lakoff, 1990 e Johnson, 1987 apud Ramos, 2005:162) "são estruturas mentais apriorísticas, arquitetadas a partir das nossas experiências corporais. [...] estão sempre sendo recodificados em nossas mentes, pois apresentam detalhes das nossas experiências diárias", derivam da interação e da observação no mundo, da experiência corporificada e são inerentemente significativos. Os esquemas imagéticos são abstratos, emergentes da experiência corporificada, derivam de experiências entre as diferentes modalidades (diferentes tipos de experiência sensorial) e decorrem de uma vasta gama de experiências perceptuais.

De acordo com Lakoff (1987 apud Evans e Green, 2006:280), os esquemas imagéticos são "blocos de construção" de suma importância na estruturação conceitual, visto que a nossa experiência sobre os conceitos de espaço é estruturada em grande parte por esquemas imagéticos. Eles estruturam os nossos MCIs para os espaços mentais e têm como base a experiência humana por meio da interação física e corporal com o mundo, com a nossa movimentação no mundo, nossa manipulação de objetos e interações perceptivas. Os esquemas imagéticos podem se sobrepor de maneira sequencial, não são estáticos. Eles são responsáveis por estruturar toda a projeção entre os espaços mentais.

Para discorrermos acerca da Teoria da Mesclagem Conceptual (TIC), precisamos das definições sobre a Teoria dos Espaços Mentais (abordada acima) e a Teoria da Metáfora Conceptual, visto que a mesclagem deriva dessas duas tradições presentes na semântica cognitiva. Porém, a TIC é estritamente mais ligada à Teoria dos Espaços Mentais, devido ao dinamismo de tal teoria na construção do significado e da sua dependência da abertura de espaços mentais em seu arquétipo.

A Teoria da Metáfora Conceptual baseia-se no mapeamento entre estruturas de conhecimentos pré-existentes para o surgimento de um novo significado. Porém, essa teoria não responde por questões que contradizem o que está sendo mapeado. Isso chama atenção para a questão de que a linguagem e o pensamento não se compõem aditivamente, ou seja, a construção do significado não pode depender exclusivamente de simples processo de projeções conceituais, realizadas na metáfora conceptual, como um conceito em termos de outro (EVANS \& GREEN, 2006). Surge a Teoria da Mesclagem Conceptual, em que a construção do significado é mais do que a soma de suas partes componentes, é uma estrutura emergente com características peculiares.

Fauconnier e Turner (apud EVANS \& GREEN, 2006) atentam para uma rede de integração que consiste em entradas cujos elementos sejam ligados por mapeamentos. Com isso, a Teoria da Mesclagem Conceptual aproxima-se da Teoria da Metáfora Conceptual; e, 
da Teoria dos Espaços Mentais, assumem a ideia de que as unidades conceituais devem ser espaços mentais e não domínios (como na Metáfora Conceptual), por que estes são estruturas de conhecimentos pré-existentes relativamente estáveis e os espaços mentais são temporários, criados durante o processo on-line de construção do significado, sendo mais momentâneo.

Os elementos que compõem a mesclagem conceptual são, pelo menos, quatro: espaço genérico, dois inputs e o espaço da mescla. O espaço genérico consiste em estabelecer conexões entre as contrapartes dos espaços de inputs. Tais conexões são estabelecidas por correspondências, realizadas por projeções conceituais.

Os espaços de entrada dão origem à projeção seletiva na mescla, isto é, nem toda a estrutura presente nos inputs é projetada no espaço da mescla, mas apenas as informações necessárias à compreensão. Algumas informações são até incompatíveis com o significado da construção emergente. Com isso, a projeção seletiva é um dos motivos pelo quais diferentes usuários da mesma língua podem produzir diversas mesclas, oriundas nos mesmos inputs. É talvez nesse aspecto que o professor de língua materna deve reter uma atenção especial. Quando as informações projetadas da mescla, oriundas dos inputs, não correspondem à construção do significado da construção que emerge do espaço mescla, a não compreensão se realiza. Se esses conceitos, oriundos da filosofia da Linguística Cognitiva, forem levados para dentro da sala de aula, o processo de construção do conhecimento sofreria reviravoltas desejadas, permitindo ao docente ampliar seu campo de conhecimento e guiar suas práticas por outros caminhos.

De acordo com Miranda (1999 apud Chiavegatto, 2009:91), “a mesclagem é o processo responsável pela dimensão criativa de todas as formas de pensamento. É pelas novas relações e pelas novas configurações que dão aos sentidos que combinam que fazem surgir novas significações e conceptualizações". A mescla é o resultado de projeções que permitem compreender o espaço único da significação.

Em relação às tiras, a notável circulação desse gênero textual em periódicos diversos, em livros didáticos, em suporte específico para eles - os gibis - e no meio virtual funciona como um elemento provocador de nossa análise, levando em consideração, de acordo com Bakthin (2003), a relação existente entre a criação e manutenção dos gêneros do discurso com as necessidades sociais de cada momento histórico.

As tiras, dentre outras características, possuem um forte apelo humorístico, que muitas vezes aparece de maneira implícita e, para que a leitura aconteça, é preciso ativar conhecimentos que existem fora do contexto de sala de aula; é neste momento que a presença do professor se faz muito necessária. Percebe-se o sentido do efeito humorístico em muitas tirinhas através da presença de metáforas conceptuais e principalmente através do processo da mesclagem conceptual. 


\section{3) Análise do Corpus}

Uma das práticas pedagógicas desenvolvidas e aplicadas para a realização deste estudo foi acerca da descrição da compreensão da tira de O Menino Maluquinho, de Ziraldo - Figura 1 - (www.ziraldo.com.br):
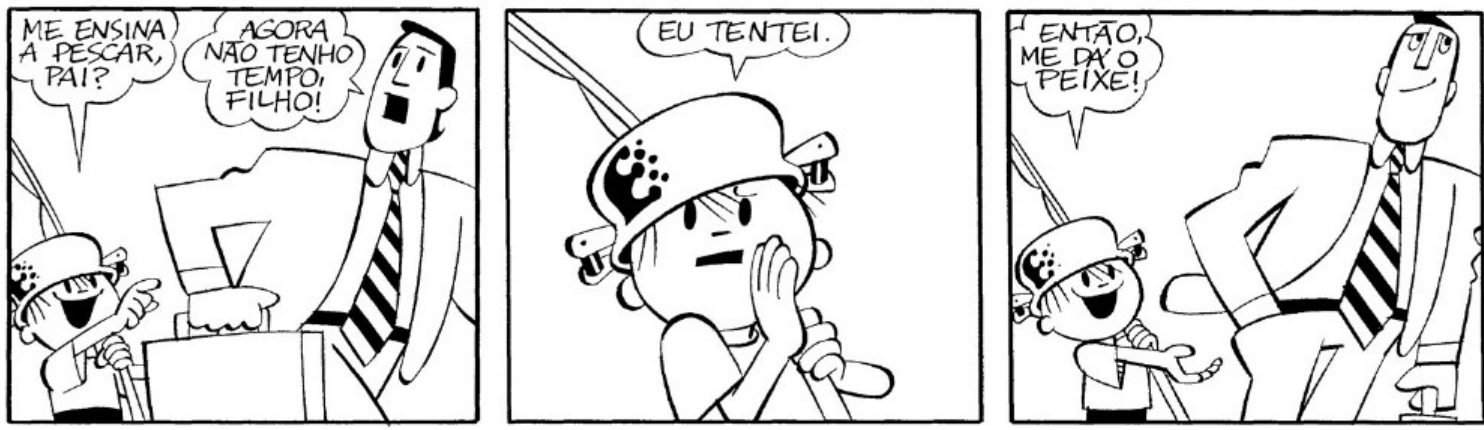

Ao realizarmos a leitura, percebemos que a construção do conhecimento está pautada no provérbio "o importante não é dar o peixe, mas ensinar a pescar", armazenado em nosso conhecimento de mundo. Essa expressão é muito utilizada para fazer referência a conseguir as coisas através de esforço, mérito e não simplesmente conquistar algo com facilidade.

É no modelo cognitivo idealizado (MCI) que está armazenado o nosso conhecimento de mundo acerca do provérbio que funciona como pano de fundo para a compreensão do texto. O cenário da tira nos remete à moldura comunicativa da pescaria, já que temos a presença do Menino Maluquinho como o "provável" pescador, caracterizado com a vara de pescar e, logo em seguida, conseguindo a aquisição do "peixe". Todos os envolvidos assumem papéis bem característicos deste tipo de moldura, já que esses aspectos determinam bem a cena na qual a interação acontece.

Ao examinarmos o código verbal do primeiro quadro da Figura 1, percebemos que as palavras "pescar" e "ensina", associada à leitura do código não verbal, funcionam como Construtores de Espaços Mentais, facilitando a abertura de espaços mentais, estruturados pelos modelos cognitivos idealizados ligados ao nosso conhecimento de pescaria e ensino. No espaço mescla é estabelecida uma relação de projeção seletiva oriunda dos input 1 (pesca) e input 2 (ensino). O espaço genérico envolve estruturas parciais desses inputs, como pescaria, pescador, aprendiz, mestre, isca, peixe, anzol, vara de pescar, ensinamento, aprendizagem etc. Através das projeções de partes em contrapartes dos inputs, surge a mescla, "Aprender é saber pescar".

Porém, ao observarmos a postura do pai e a sua fala, associada à leitura do segundo quadro, percebemos que a criança faz uma tentativa de aprendizado em vão, pois a falta de 
tempo do pai faz com que os conhecimentos acerca da pescaria não sejam repassados. É no último quadro que a compreensão da tira se realiza. É na relação entre a leitura dos códigos verbal e não verbal associada ao nosso conhecimento enciclopédico que a construção do conhecimento se realiza. Ao pronunciar a frase "Então me dá o peixe", a palavra "peixe" funciona como um construtor de novos espaços mentais em que o input 3 contém informações referentes ao pai, Menino Maluquinho (filho), peixe, pescaria etc. Já o input 4 fornece informações acerca de trabalho, dinheiro, lazer etc. A mescla "O peixe é o dinheiro" ocorre através das projeções das contrapartes dos inputs 3 e 4 e da outra mesclagem obtida pelos inputs 1 e 2. É nesse novo espaço mescla que ocorre a relação entre o conteúdo da tirinha e o dito popular, fazendo com que a leitura deixe de ser literal e passe para o campo metafórico. O esquema abaixo é uma tentativa de ilustrar como esses fenômenos cognitivos são processados na mente:

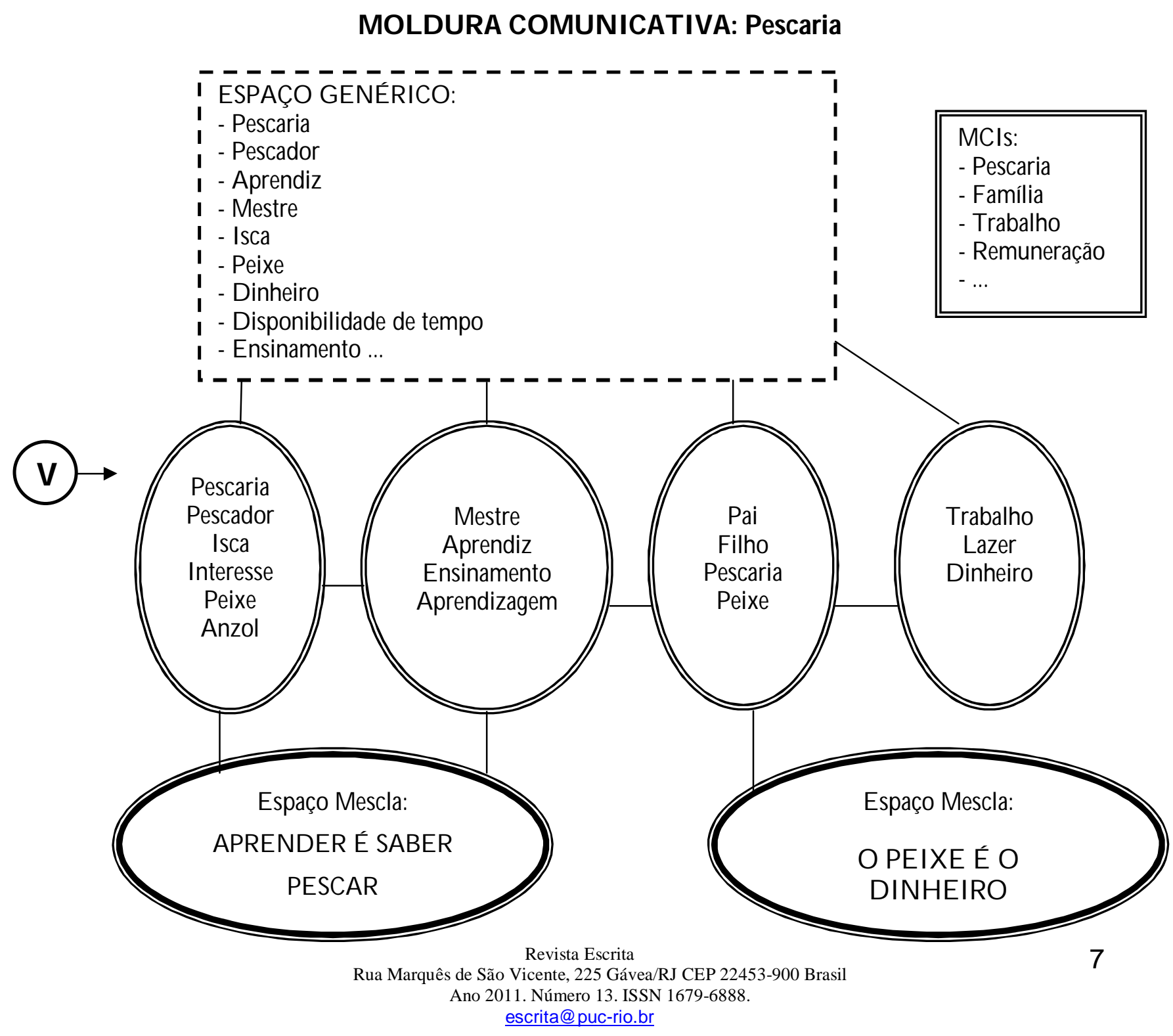


Uma outra prática pedagógica desenvolvida utilizou a Figura 2 (www.monica.com.br) como material para o estudo da compreensão leitora dos alunos, em que é possível identificarmos vários aspectos relevantes para a compreensão: a personagem Magali caracterizada de Eva - mulher de Adão (ambos personagens bíblicos), a maçã (fruto proibido) e a serpente (desencaminhadora).
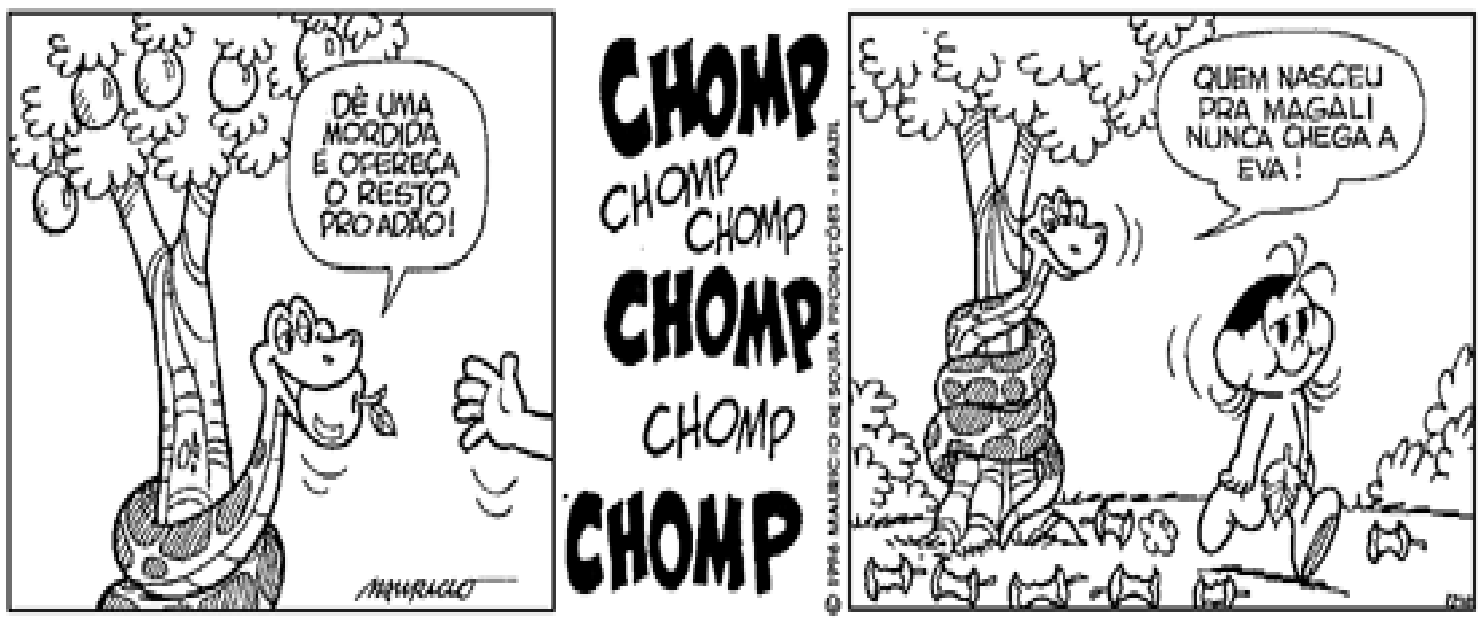

Copyright (C) 1999 Mauricio de Sousa Produộ́es Ltda. Todos os direitos reservados.

7146

Após a leitura da tira, é possível descrever todos os processos cognitivos envolvidos na construção do significado. Cognitivamente, a moldura cognitiva identificada é a representação de uma passagem bíblica ou religião. Os MCIs de religião, paraíso, pecado estruturam o espaço mescla onde é estabelecida uma relação de projeção seletiva oriunda dos input 1 e input 2. O espaço genérico envolve estruturas parciais desses inputs, como fruto proibido, serpente, Magali, Adão, Eva, gula, desrespeito, imprudência etc. Através das projeções de partes em contrapartes dos inputs, surge a mescla, "Quem nasceu para Magali nunca chega a Eva!".

Observe o esquema abaixo que ilustra o processo de projeção e mesclagem acerca da compreensão da tirinha analisada: 


\section{MOLDURA COMUNICATIVA: Passagem bíblica ou religião}

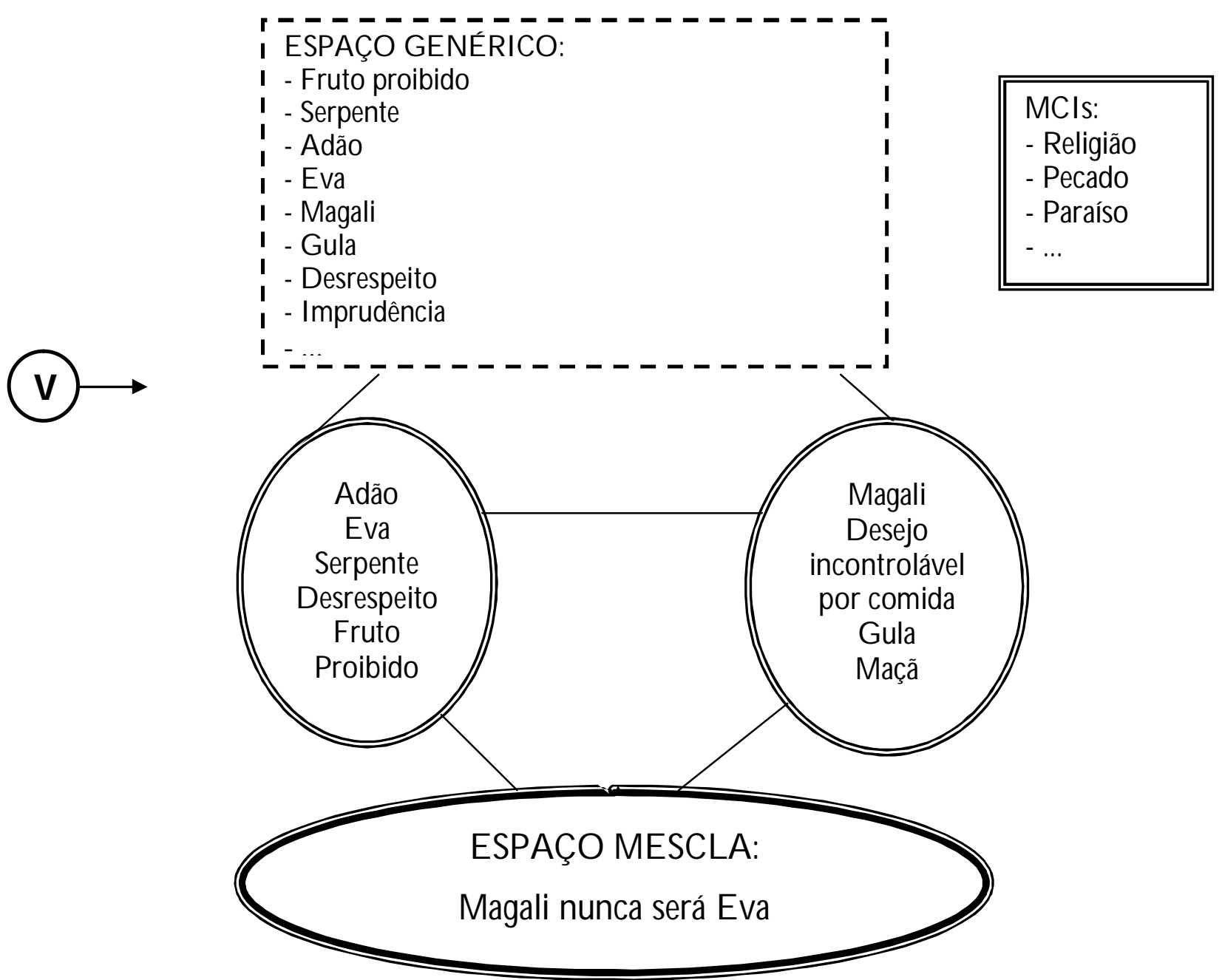

\section{4) Contexto da Pesquisa e Aplicação das Práticas Pedagógicas}

Essas práticas pedagógicas foram aplicadas em uma turma de $9^{\circ}$ ano de uma escola pública do município de Duque de Caxias. A turma é composta de 24 alunos com faixa etária média entre 15 e 17 anos que residem na comunidade carente do bairro de Imbariê.

A maioria dos alunos tem pouco contato com a leitura, ficando essa atividade restrita ao espaço escolar. Muitos possuem sérias dificuldades de leitura e são poucos aqueles que conseguem ultrapassar a decodificação do código linguístico. A maioria dos discentes não consegue fazer uma leitura em sentido pleno. 
A escolha de se trabalhar com tiras surgiu durante a observação da dificuldade dos alunos ao lidar com esse gênero. Apesar de as tiras serem muito populares entre os discentes, elas necessitam de uma leitura que vai além da decodificação; necessitam da ativação de conhecimento prévio, do estabelecimento de intertextualidades, de reconhecimento da ironia, entre outros. Os estudantes não conseguem, em sua maioria, perceber o tom humorístico tão característico desse gênero.

A prática pedagógica, utilizando a Figura 1, revelou dados interessantes: dos vinte e dois alunos que entregaram a descrição daquilo que entenderam ao ler a tira, apenas três (13\%) conseguiram obter a construção do significado, através das projeções metafóricas e do processo de mesclagem. A maioria dos alunos ficou na literalidade das palavras, não conseguindo fazer as projeções que permitem a compreensão da tira por meio metafórico, relacionando-a com o provérbio, que funciona como pano de fundo, pertencente a nossa cultura.

A segunda prática pedagógica desenvolvida, utilizando a Figura 2, também revelou dados interessantes. Dos vinte e dois alunos que desenvolveram a atividade de descrição acerca daquilo que compreenderam após a leitura da tira, apenas quatro (18\%) conseguiram realizar a construção do significado. A maioria dos alunos não conseguiu ativar os conhecimentos prévios, associação à passagem bíblica de Adão e Eva, necessários para a compreensão. Esses alunos apenas fizeram a decodificação do código linguístico, não conseguindo realizar as projeções metafóricas para o surgimento da mescla.

\section{5) Estudos de Caso}

Selecionamos, aleatoriamente, as práticas pedagógicas de dois alunos que não conseguiram realizar a construção do conhecimento exigida pelas leituras das tiras de $O$ Menino Maluquinho e da Turma da Mônica a fim de que possamos analisar onde ocorre a dificuldade de compreensão das tiras como um todo.

$\mathrm{Na}$ primeira prática pedagógica desenvolvida, utilizando a tira de $\mathrm{O}$ Menino Maluquinho - Figura 1 - o aluno fez a seguinte descrição "Eu entendi que o menino queria que o pai 'ensina-se' ele a 'pesca'. Mas o pai dele estava com pressa para trabalhar. O garoto disse: Eu tentei 'pedi'o meu pai. Então ele deu o dinheiro para comprar o peixe" (anexo 1).

A descrição acima indica que, ao realizar a leitura, o aluno não conseguiu ultrapassar a literalidade das palavras, não conseguiu estabelecer a relação existente entre a informação presente na tira com o dito popular. $\mathrm{O}$ aluno fez uma leitura em que ficou preso ao significado literal das palavras, não realizando as projeções metafóricas entre os inputs, não sendo possível assim surgir o espaço-mescla, onde o sentido metafórico da palavra 
"peixe" emerge. As expressões "ensinar a pescar" e "me dá o peixe" não foram processadas como expressões metafóricas que nos remetem a informações pertencentes ao nosso conhecimento enciclopédico, mas sendo interpretadas em seu sentido restrito.

Uma tentativa de compreensão acerca da descrição desse aluno é a de que os inputs 1 e 2 contêm apenas as informações referentes à pescaria e ensino, respectivamente. Não surgem os inputs 3 e 4 responsáveis pelas projeções seletivas para o surgimento da mescla "O peixe é o dinheiro", porque o aluno não foi capaz de entender as expressões além de seu sentido básico. Com isso, podemos perceber também que o conhecimento armazenado a respeito do provérbio "o importante não é dar o peixe, mas ensinar a pescar" não foi acionado, ficando a leitura restrita apenas à superficialidade, não percebendo assim o humor que perpassa por toda a tira, obtido por meio do processo de projeções metafóricas e mesclagem.

O esquema abaixo é uma tentativa de ilustrar o processo de projeção e mesclagem acerca da compreensão realizada pelo aluno:
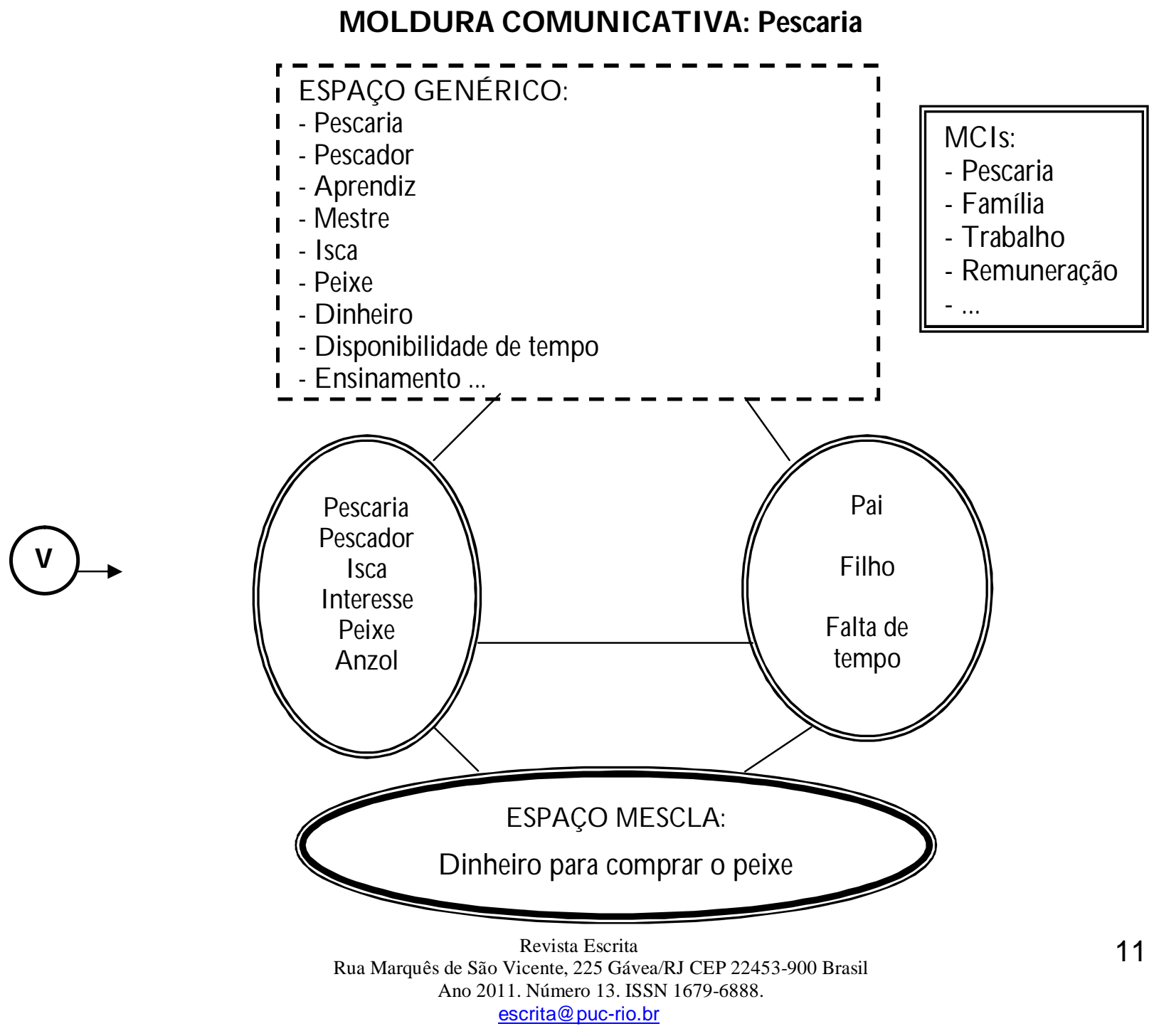
Com esse exemplo, foi possível perceber que

o insucesso dessa prática pode revelar a inadequação da composição referencial provida em aula, pois o ensino deve ser reflexivo e sensitivo para a possibilidade de diferentes entendimentos. Assim, ao repensarmos as práticas pedagógicas, devemos estimular os alunos a perceberem que as projeções metafóricas constroem sentido no texto e em diferentes práticas da vida diária (MORAIS, 2005, p.100).

Na segunda prática pedagógica - Figura 2 - o aluno escreveu "A cobra 'o fereceu' a 'maça' pra Magali e o resto 'da' pro 'adão' mas ela comeu tudo pra não 'da' pra eles” (anexo 2). Após a leitura dessa descrição, podemos perceber que o aluno realizou apenas a decodificação do código linguístico, não realizando a ativação dos conhecimentos prévios necessários, tais como a passagem bíblica que funciona de pano de fundo para que o humor da tira se realize, que tem como personagens Adão, Eva e a serpente; característica marcante da personagem Magali, conhecida pela sua infinita gula, que também é um dos sete pecados. Em momento nenhum, em sua descrição, o aluno cita que a Magali é conhecida por sua imensa vontade de comer, apenas diz que ela "comeu tudo", sem ao certo mencionar o seu conhecimento a respeito dessa personagem.

A análise realizada abaixo é uma tentativa de descrever o processo realizado para a construção de conhecimento desse aluno com base na leitura da Figura 2:

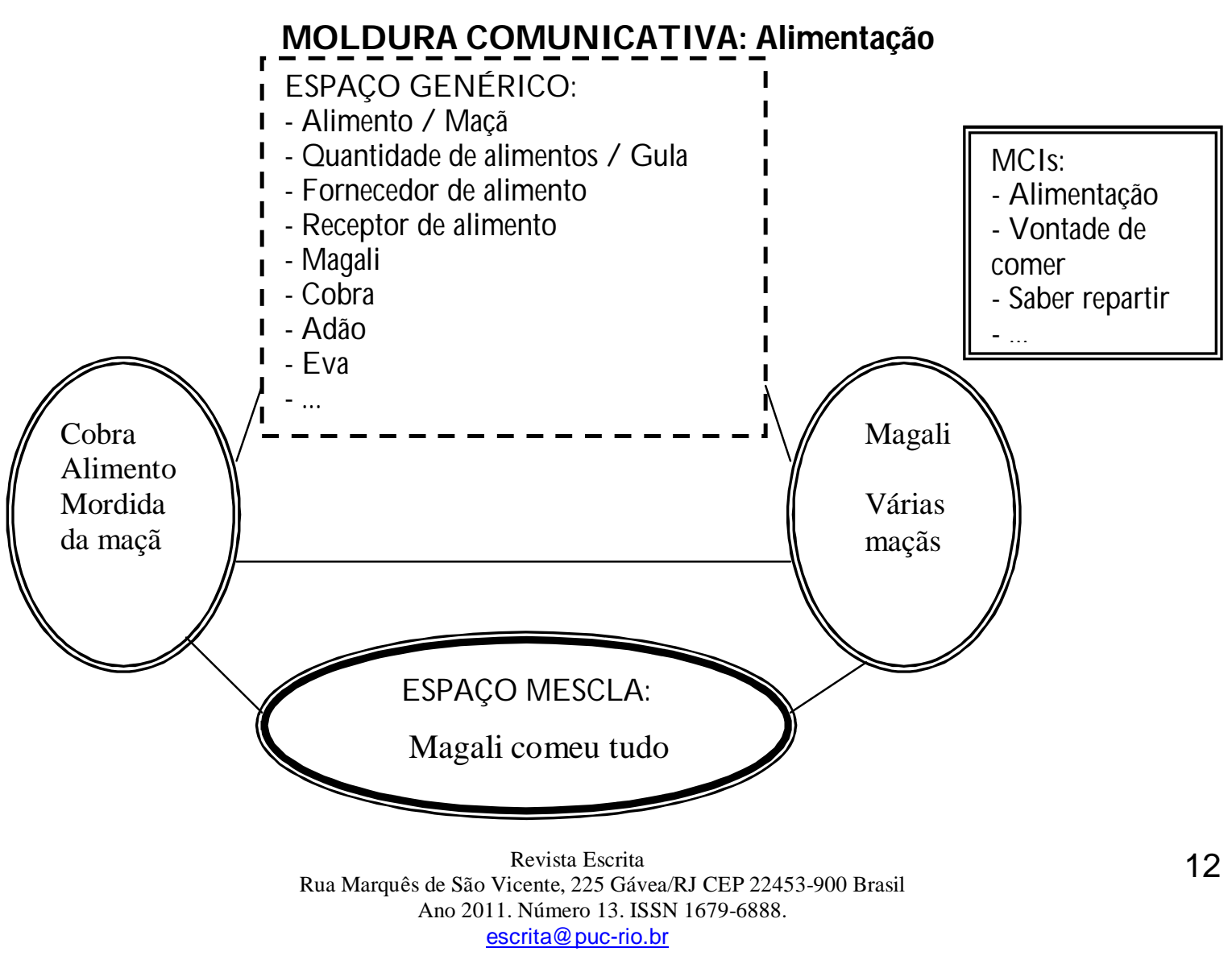


A análise, pautada na descrição realizada pelo aluno, é a de que os inputs 1 e 2 contêm apenas as informações referentes a quem oferece o alimento e a quem o recebe, respectivamente. $\mathrm{O}$ aluno não acessou as informações disponíveis referentes à passagem bíblica, Adão, Eva, serpente, gula, valor metafórico da maçã, gula etc. que correspondem a itens essenciais responsáveis pelas projeções seletivas para o surgimento da mescla "Magali nunca será Eva", porque fez apenas a decodificação das palavras, não sendo capaz de entender as expressões além de seu sentido literal. Com isso, pode-se perceber que a leitura ficou restrita à superficialidade, não sendo possível a construção do conhecimento obtido por meio do processo de projeções metafóricas e mesclagem. O sentido metafórico das expressões presentes não foi obtido e a compreensão da tira não se realizou.

\section{6) Considerações Finais}

Neste artigo, expuseram-se, sob os vieses sociocognitivo e sociointeracional, os procedimentos inerentes à construção do significado através de análise de duas práticas pedagógicas com tirinha. Por meio dessas análises, foi possível observar que, corroborando estudos realizados nessa área como de Ramos (2005), Morais (2005) e Saliés (2001), as projeções constituem uma área fecunda de estudos quando se almeja analisar como se dá a construção de significado na mescla.

A descrição realizada acerca dos conceitos de molduras comunicativas, modelos cognitivos idealizados, esquemas imagéticos, espaços mentais e sobre a Teoria a Mesclagem Conceptual são de suma importância quando se tem em mente estudar os processos cognitivos que envolvem o significado.

Com os estudos de caso realizados, pôde-se perceber que os alunos, em sua maioria, não conseguem ir além da decodificação do código linguístico em atividades de compreensão leitora, ficando restritos apenas à literalidade das palavras, não sendo capazes de perceber o sentido metafórico das expressões. O tom humorístico que perpassa a leitura de tiras não é notado, visto que os discentes não acionam as informações necessárias para a realização das projeções metafóricas responsáveis pelo surgimento da mescla. Quando essas projeções não ocorrem adequadamente, a construção do significado não acontece.

Pretendemos levar esses conhecimentos aqui observados novamente para a sala de aula de língua materna e aplicar novas práticas pedagógicas já elaboradas por Ramos (2006), a partir também de um corpus de tirinhas, para colhermos novas informações, com o intuito de perceber como as projeções e as mesclas são realizadas pelos discentes em turmas de ensino básico, após a realização de intervenções necessárias. Percebemos, a princípio, que o problema de compreensão no processo de leitura reside justamente nas 
realizações dessas projeções. A pesquisa será de natureza aplicada, conjugando os modelos de uma pesquisa ação e um estudo de caso, porque objetiva gerar conhecimentos, já que aplicaremos novas práticas pedagógicas, colheremos resultados para análise dos dados e faremos uma análise qualitativa e comparativa (antes e depois das intervenções) desses dados de modo a interpretá-los, buscando atribuir significados aos fenômenos observados.

\section{7) Referências Bibliográficas}

BAKHTIN, Mikhail. Estética da criação verbal. 4 ed. São Paulo: Martins Fontes, 2003.

CHIAVEGATTO, Valéria Coelho. Introdução à Linguística Cognitiva. Matraga. Rio de Janeiro, RJ: UERJ, vol. 16, jan.-jun., n. 24, 2009, p. 77-96.

EVANS, Vyvyan \& GREEN, Melanie. Cognitive linguistics: an introduction. Edinburgh: Edinburgh University Press, 2006.

FAUCONNIER, G. Mappins in Trought and Language. Cambridge: Cambridge University Press, 1997.

LAKOFF, George. Women, Fire, and Dangerous Things: What Categories Reveal about the Mind. Chicago: The University of Chicago Press, 1987.

MARCUSCHI, L. A. Produção textual, análise de gêneros e compreensão. São Paulo: Parábola Editorial, 2008.

MIRANDA, N.S. Domínios conceptuais e projeções entre domínios: uma introdução ao Modelo dos Espaços Mentais. Revista Veredas, Juiz de Fora, v. 3, n. 1, p. 81-95, 1999.

MORAIS. M.B.E. Reflexões sobre o processo de leitura de uma turma de $6^{\mathrm{a}}$ série do ensino fundamental: uma abordagem ecológica. 2005. 127 f. Dissertação (Mestrado em Linguística) - UERJ, Rio de Janeiro, 2005.

RAMOS, A. P. M. Esquemas imagéticos e o processo de mesclagem no gênero "tirinhas". Linguagem: Teoria, Análise e Aplicações. Rio de Janeiro, RJ: UERJ, 2005.

RAMOS, Ana Paula Moraes. Ensino de Leitura Em Língua Materna: Práticas Pedagógicas Sob A Ótica Sociocognitiva Inspiradas por Corpus de 'tirinhas'. Linguagem: Teoria, Análise e Aplicações (2). CD-ROM. Rio de Janeiro, RJ: UERJ, 2006.

SALIÉS. T.G. Esquemas-imagéticos: contrastando o português e o inglês. Anais do VI Congresso Brasileiro de Linguística Aplicada. Universidade Federal de Belo Horizonte: ALAB. CD-ROM, 2001. 


\section{8) Anexos}

\section{Anexo 1:}

Nome:

Turma: 903

Leia a tirinha abaixo:
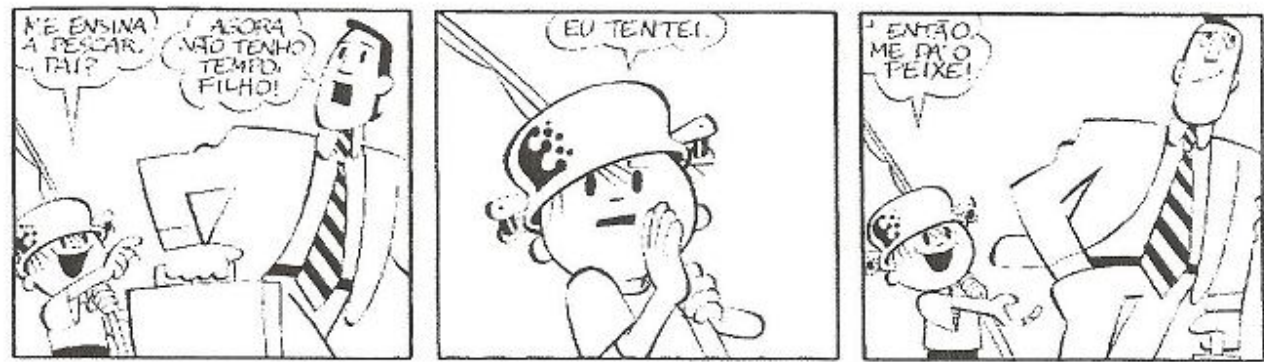

Descreva o que você compreendeu da tírinha acima.

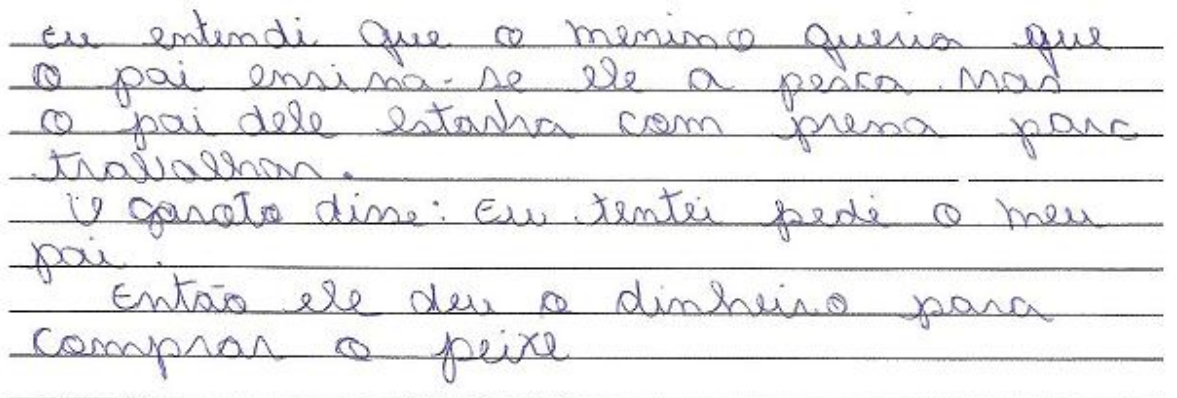

Anexo 2: 
Leia a tirinhá abaixo:
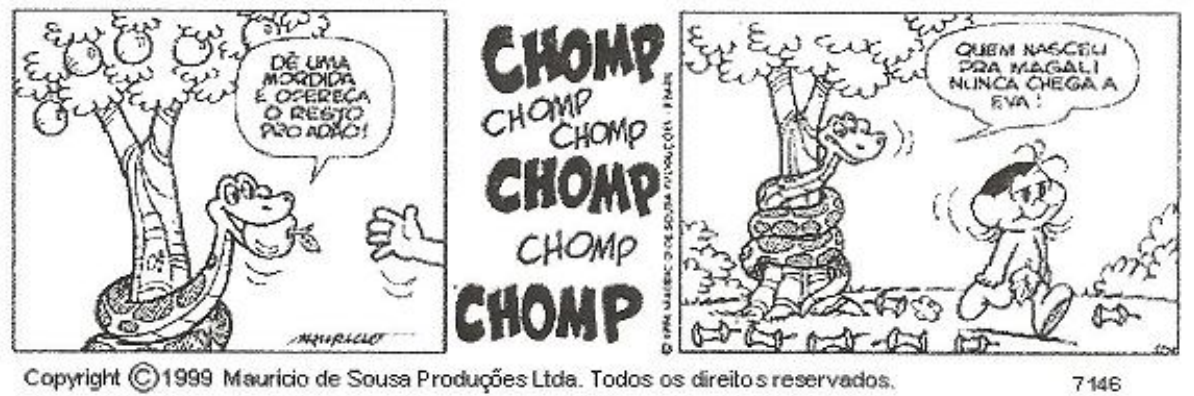

Copyright (C)1999 Mauricio de Sousa Produçôes Ltda. Todos os direitos reservados.

Descreva o que você compreendeu da tirinha acima.

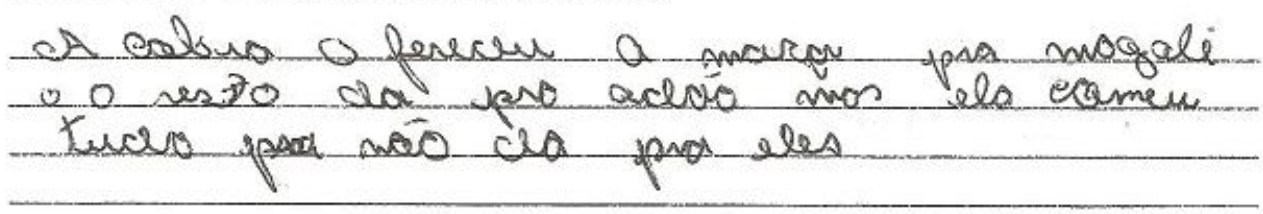

